This is the final peer-reviewed accepted manuscript of:

(E)-3-(Alkoxycarbonyl-2-Alkyliden)-2-Oxindoles: Multidentate Pronucleophiles for the Organocatalytic, Vinylogous Michael Addition to Nitroolefins, Curti, Claudio; Battistini, Lucia; Sartori, Andrea; Rassu, Gloria; Pelosi, Giorgio; Lombardo, Marco; Zanardi, Franca, ADVANCED SYNTHESIS \& CATALYSIS, 2018, 360 (4), 711-721.

The final published version is available online at: https://doi.org/10.1002/adsc.201701164

Rights / License:

The terms and conditions for the reuse of this version of the manuscript are specified in the publishing policy. For all terms of use and more information see the publisher's website.

This item was downloaded from IRIS Università di Bologna (https://cris.unibo.it/)

When citing, please refer to the published version. 


\title{
(E)-3-(Alkoxycarbonyl-2-Alkyliden)-2-Oxindoles: Multidentate Pronucleophiles for the Organocatalytic, Vinylogous Michael Addition to Nitroolefins
}

\author{
Claudio Curti, ${ }^{\text {a* }}$ Lucia Battistini, ${ }^{\text {a }}$ Andrea Sartori, ${ }^{\mathrm{a}}$ Gloria Rassu, ${ }^{\mathrm{b}}$ Giorgio Pelosi, ${ }^{\mathrm{c}}$ \\ Marco Lombardo, ${ }^{\mathrm{a}}$ and Franca Zanardi ${ }^{\mathrm{a}}$
}

a Dipartimento di Scienze degli Alimenti e del Farmaco, Università di Parma, Parco Area delle Scienze 27A, 43124 Parma, Italy

Fax: (+ 39)-0521-905006; phone: (+ 39)-0521-905080, e-mail: claudio.curti@unipr.it

b Istituto di Chimica Biomolecolare del CNR, Traversa La Crucca 3, 07100 Li Punti, Sassari, Italy

c Dipartimento di Scienze Chimiche, della Vita e della Sostenibilità Ambientale, Parco Area delle Scienze 17A, 43124

Parma, Italy

d Dipartimento di Chimica “G. Ciamician”, Università degli Studi di Bologna, Via Selmi 2, 40126 Bologna, Italy

Received: ((will be filled in by the editorial staff))

Supporting information for this article is available on the WWW under http://dx.doi.org/10.1002/adsc.201\#\#\#\#\#\#.((Please delete if not appropriate))

\begin{abstract}
We introduce 3-(alkoxycarbonyl-2-alkyliden)-2oxindoles as pronucleophilic donors in the direct, vinylogous Michael addition to nitroolefins orchestrated by a chiral, bifunctional cinchona-thiourea organocatalyst. This reaction displays excellent levels of $\gamma$-site-, diastereo- and enantioselectivity delivering valuable enantioenriched functionalized oxindoles. Of note, the $\mathrm{C}-\gamma$ enolization of these pronucleophiles by the organocatalyst generates a multidentate, captodative dienolate that delivers vinylogous adducts with an unprecedented $Z$-selectivity through a peculiar interaction with the catalyst and the nitroolefin.
\end{abstract}

\section{Introduction}

The last 15 years have witnessed the flourishing of asymmetric organocatalysis as a pivotal methodology for the stereoselective synthesis of natural products, chiral drugs and building blocks under mild and usually environment-friendly conditions. ${ }^{[1]}$ In this field, cinchona alkaloid-based thioureas (Figure 1) emerged as powerful chiral organocatalysts for a large number of enantioselective transformations. ${ }^{[2]}$ In fact, the thiourea hydrogen-bond donor ability linked to the quinuclidine basic character enable the coordination and activation of both the nucleophilic and the electrophilic partners of many reactions by noncovalent interactions. In addition, since these two acid/base cooperating moieties usually confer rigidity and tightness to the transition state, constraining it to a defined geometry, the transfer of the chiral
The optimized procedure is operatively simple: the reaction is conducted in air, at room temperature, with low catalyst loading (up to $1 \mathrm{~mol} \%$ ). The synthetic versatility of these Michael adducts is demonstrated by several transformations leading to a valuable quaternary oxindolyl proline analogue and a chiral spirocyclic furoindolone structure. Finally, a mechanistic rationale and a suitable transition state accounting for the observed selectivities are proposed, which are supported by DFT calculations.

Keywords: asymmetric catalysis; density functional calculations; organocatalysis; oxindoles; vinylogous Michael reaction information by the catalyst to the products often results successful.

In the field of organocatalysis, within the toolbox of synthetic transformations currently under scrutiny by the organic chemistry community, vinylogous reactions based on the reactivity of in situ-generated di- or polyenolates have become a topic of particular relevance.
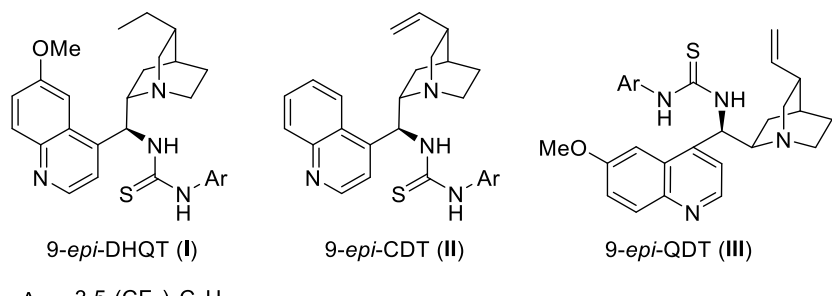

$\mathrm{Ar}=3,5-\left(\mathrm{CF}_{3}\right)_{2} \mathrm{C}_{6} \mathrm{H}_{3}$

Figure 1. Representative bifunctional cinchona alkaloidthiourea catalysts. ${ }^{[2]}$ 
Consequently, mastering the behaviour of these inherently polydentate vinylogous nucleophiles in a chemo-, regio-, and stereocontrolled way is of utmost importance to render vinylogy a really useful option in synthesis. $^{[3]}$

In this context, we recently developed the first example of a direct, organocatalytic and enantioselective vinylogous Michael addition of 3alkylidene oxindoles of type $\mathbf{C}$ (Scheme 1) to nitroolefins, nicely orchestrated by hydroquininederived bifunctional thiourea catalyst I (Figure 1). ${ }^{[4 a, 4 b]}$ Easily accessible by Knoevenagel condensation of 2oxindoles A with suitable enolizable carbonyl acceptors $\mathbf{B}$, these viable pronucleophiles afforded the corresponding $\gamma$-substituted 3-alkylidene oxindoles D with outstanding levels of regio- and stereocontrol (Scheme 1, dashed frame).

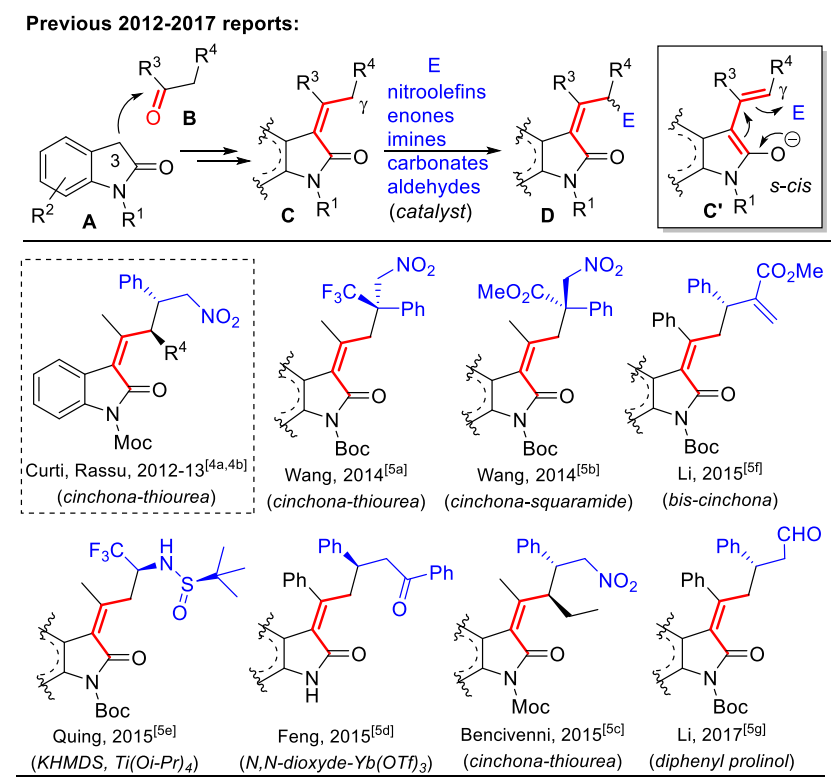

Scheme 1. Reactivity and scope of pronucleophilic 3alkylidene oxindoles of type $\mathbf{C}$ : representative examples of up-to-date addition reactions. In parenthesis the catalytic system used.

Since then, other groups have exploited similar pronucleophiles in the organo- or metal-catalyzed addition to various electrophilic partners such as nitroalkenes, ${ }^{[5 \mathrm{a}-\mathrm{c}]}$ enones, ${ }^{[5 \mathrm{~d}]}$ imines, ${ }^{[\mathrm{se}]}$ Morita BaylisHillman (MBH) carbonates, ${ }^{[5 f]}$ and aldehydes, ${ }^{[5 \mathrm{~g}]}$ thus confirming the high viability and versatility of this class of vinylogous pronucleophiles in synthesis.

Interestingly, the selective C- $\gamma$ homologation of all the tested 3-alkylidene oxindoles was achieved with high efficiency and stereoselectivity, invariably giving the corresponding oxindole products with geometrically defined, cis-disposed olefins (i.e. the newly installed chain is positioned on the same side with respect to the oxindole carbonyl), as detailed in Scheme 1. ${ }^{[6]}$ In all instances, s-cis dienolate conformations of type $\mathbf{C}^{\prime}$ are likely to be operative in the stereodetermining transition states, which dictate the final geometry of the products.
It is well known that the specific topology and geometry asset of olefins within unsaturated natural and unnatural bioactive molecules is of utmost importance in medicinal chemistry and biology, since in most cases it significantly affects the overall bioactivity of the molecule. In this context, the $Z / E$ nature of the exocyclic double bond within scaffolds $\mathbf{D}$ is particularly relevant, since 3-alkylidene oxindoles are the core structure of a wide range of biologically and pharmaceutically relevant molecules. ${ }^{[7 a]}$ One notable example is sunitinib, an alkylidene oxindole multi-targeted receptor tyrosine kinase (RTK) inhibitor, which is highly active and stable only in its Z-configuration. ${ }^{[\mathrm{7b}, \mathrm{c}]}$

Continuing on this theme, we became interested in the chemistry of pyruvate-like structures of type $\mathbf{E}$ (Scheme 2), an appealing set of compounds that appear in most crucial steps of biochemical processes as either donor or acceptor components. ${ }^{[8]}$ In particular, due to their high degree of functionalization, $\alpha$-enolizable 2ketoesters have raised wide interest in the field of organic synthesis, and in recent years their role as valuable $d^{2}$-synthons has been reconsidered and exploited. ${ }^{[9]}$

We envisioned that merging the 2-oxindole scaffold A with an enolizable 2-ketoester $\mathbf{E}$ would result in the formation of 3-(alkoxycarbonyl-2-alkyliden)-2oxindole 1, a vinylogous variant of $\mathbf{E}$ that retains its pronucleophilic character at $\mathrm{C}-\gamma$, while significantly expanding its reactivity space. To date, several nonenolizable compound analogues are known and well exploited as electrophilic species in a vast array of transformations spanning from Michael-type reactions to one-pot or multistep cycloadditions $;{ }^{[10]}$ however, the pronucleophilic character of such substrates remains elusive and substantially unexplored.

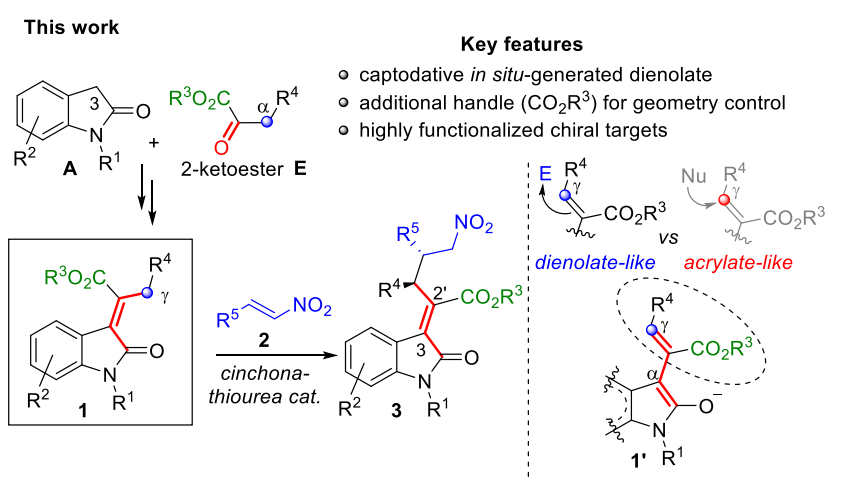

Scheme 2. Overview of the present work based on the exploitation of "pyruvate-oxindole merger" 1 as vinylogous pronucleophile.

Interestingly, the $\mathrm{C}-\gamma$ enolization of $\mathbf{1}$ would generate a multidentate dienolate 1' embedding an exocyclic, captodative olefin, ${ }^{[1]}$ whose dual nature is intriguing: in principle, it may act either as a vinylogous nucleophile in a "dienolate-like" fashion (Scheme 2, right) or, conversely, it may work as an "acrylate-like" moiety where the C- $\gamma$ acts as an electrophilic site. 
Moreover, we reasoned that the additional ester handle could play an active role in the interaction with the catalyst in the transition state, thus influencing the geometry outcome of the products.

Intrigued by the new opportunities these scaffolds could drive in terms of site-, geometry-, and stereoselectivity, we embarked in a project toward the exploitation of "pyruvate-oxindole merger" of type 1 as pronucleophilic donor in the direct and vinylogous Michael addition (VMcR) to nitroolefins 2 orchestrated by a chiral, bifunctional cinchonathiourea organocatalyst (Scheme 2, left). The success of this endeavour is here reported, as demonstrated by the straightforward entry to a collection of multifunctionalized and highly enantioenriched oxindoles of type 3. Also, the synthetic usefulness of these products was proven, by easy transformation of some representative compound into a quaternary oxindole-proline and a chiral spirocyclic furoindolone structure. Finally, several DFT analyses are reported to support a mechanistic rationale and a suitable transition state that account for the observed selectivities.

\section{Results and Discussion}

\section{Viability and Optimization Survey}

To test the viability of the planned VMcR, we chose $\mathrm{N}$-Moc-3-(methoxycarbonyl-2-butylidene)-2- oxindole (1a) and trans- $\beta$-nitrostyrene (2a) as the model substrates (Table 1). Oxindole 1a, in turn, could be easily obtained via a three-step sequence starting from 2-oxindole and methyl-2-oxobutanoate via Knoevenagel-type condensation chemistry (see the Supporting Information). Initially, several bifunctional organocatalysts, including cinchona-thiourea catalysts I-III (Figure 1), cinchona-squaramide and others were screened, as detailed in Table S1 in the Supporting Information.

In particular, starting from a readily available $3: 1$ $(Z / E)$ mixture of 1a and nitroalkene 2 a (2 equiv), the best hit was achieved with hydroquinine-derived 9epi-DHQT (I), which afforded nitroalkylidene adduct 3aa in an acceptable yield (53\%) as a 1:1 Z/E mixture of geometric isomers, with complete $\gamma$-site selectivity, full 3',4'-syn diastereoselectivity and almost complete enantioselectivity (Table 1 , entry 1 ).

Despite these preliminary encouraging results, we soon noticed that the reaction was scarcely reproducible, and many attempts to improve its efficiency and $Z / E$ selectivity met with only partial success. To better understand this unpredictable behaviour, we separately reacted either oxindoles $(E)$ $\mathbf{1 a}$ or $(Z)-\mathbf{1}$ a with $\mathbf{2 a}$, using catalyst $\mathbf{I}$ as the promoter (entries 2 and 3). Surprisingly enough, we found that pure $(E)$-1a reacted efficiently with $\mathbf{2 a}$, affording 3aa in a good $85 \%$ yield after only $3 \mathrm{~h}$ reaction time and with complete enantiocontrol ( $>99 \%$ ee).

Table 1. Selected optimization studies for the direct, enantioselective VMcR between oxindoles 1a-b and olefin $\mathbf{2 a} .^{\text {[a] }}$

\begin{tabular}{|c|c|c|c|c|c|c|c|c|}
\hline & $\begin{array}{l}\mathrm{R}^{\prime} \\
\text { 1a: } \mathrm{R}^{1} \\
\mathbf{1} \mathbf{b}: \mathrm{R}^{1}\end{array}$ & & $2 a$ & $\frac{\mathrm{I}-\mathrm{III}(}{\text { tene }[0.1 \mathrm{M}]}$ & $\begin{array}{l}\text { ol\%) } \\
\left({ }^{\circ} \mathrm{C}\right), t(\mathrm{~h}\end{array}$ & & $\begin{array}{l}0 \\
20: 1 d r\left(3^{\prime}, 4\right. \\
: R^{1}=M o c \\
R^{1}=B o c\end{array}$ & \\
\hline entry & 1 & 3 & $\begin{array}{l}\text { Catalyst } \\
(\mathrm{mol} \%)\end{array}$ & $\mathrm{T}\left[{ }^{\circ} \mathrm{C}\right]$ & $t[\mathrm{~h}]$ & $\begin{array}{l}\text { Yield } \\
{[\%]^{[b]}}\end{array}$ & $Z: E^{[\mathrm{c}]}$ & $e e \%[Z / E]^{[\mathrm{d}]}$ \\
\hline 1 & $(Z / E)-\mathbf{1 a}$ & $3 \mathbf{a a}$ & I (10) & 40 & 12 & 53 & $1: 1$ & 98/99 \\
\hline 2 & $(E)-\mathbf{1 a}$ & $3 \mathbf{a a}$ & I (10) & 40 & 3 & $85(69)$ & $4.2: 1$ & $>99 / 99$ \\
\hline 3 & $(Z)-\mathbf{1 a}$ & $3 \mathbf{a a}$ & I (10) & 40 & 144 & $80(48)$ & $1.5: 1$ & 99/99 \\
\hline 4 & $(E)-\mathbf{1 a}$ & $3 \mathbf{a a}$ & I (10) & -15 & 16 & $80(73)$ & 10.6:1 & $>99 / \mathrm{nd}$ \\
\hline 5 & $(E)-\mathbf{1 b}$ & $3 \mathbf{b a}$ & I (10) & -15 & 16 & $73(65)$ & $8.3: 1$ & $>99 / \mathrm{nd}$ \\
\hline 6 & $(E)-\mathbf{1 b}$ & $3 \mathbf{b a}$ & II (10) & -15 & 16 & $73(65)$ & $11.5: 1$ & $>99 / \mathrm{nd}$ \\
\hline 7 & $(E)-\mathbf{1 b}$ & $3 \mathbf{b a}$ & II (5) & -15 & 24 & $63(52)$ & $11: 1$ & $>99 /$ nd \\
\hline 8 & $(E)-\mathbf{1 b}$ & $3 \mathbf{b a}$ & II (3) & -15 & 24 & $50(45)$ & $9: 1$ & $>99 / \mathrm{nd}$ \\
\hline 9 & $(E)-\mathbf{1 b}$ & $3 \mathbf{b a}$ & II (1) & 40 & 48 & $33(30)$ & $9: 1$ & $>99 /$ nd \\
\hline $10^{[\mathrm{e}]}$ & $(E)-1 b$ & $3 \mathbf{b a}$ & II (3) & r.t. & 16 & 98(93) & $13: 1$ & $>99 / \mathrm{nd}$ \\
\hline $11^{[\mathrm{e}]}$ & $(E)-\mathbf{1 b}$ & $3 \mathbf{b a}$ & III (3) & r.t. & 16 & 50 & $10: 1$ & $>99 / \mathrm{nd}$ \\
\hline $12^{[\mathrm{e}]}$ & $(E)-\mathbf{1 b}$ & $3 \mathbf{b a}$ & III (10) & r.t. & 24 & 70 & $8: 1$ & $-99 /-98$ \\
\hline
\end{tabular}

[a] Unless otherwise noted, all reactions were carried out on a $0.2 \mathrm{mmol}$ scale of 1a or 1b [0.1M] using 2a (2 equiv), catalyst I, II or III in toluene at the reported temperature $\left({ }^{\circ} \mathrm{C}\right)$ for the indicated period $(\mathrm{h})$.

${ }^{[b]}$ Isolated combined yield after chromatographic purification. Isolated yield of major isomer (Z)-3 in parenthesis.

${ }^{[c]}$ Determined by ${ }^{1} \mathrm{H}$ NMR of the crude.

[d] Determined by chiral HPLC analysis.

[e] 1.5:1 (1b:2a) molar ratio was used. 
Of note, product 3aa could be obtained as a separable 4.2:1 mixture of geometric isomers, the major isomer being the $Z$-configured 3aa, featuring an unprecedented trans disposition between the nitroalkylidene side chain and the oxindole carbonyl (entry 2). Conversely, the reaction between pure (Z)1a and 2a proved to be much slower and less selective than the geometric isomer, yielding 3aa in a $80 \%$ combined yield after $144 \mathrm{~h}$ reaction time as a 1.5:1 $\mathrm{Z} / \mathrm{E}$ mixture of enantiopure isomers (entry 3 ). Aware that the fixed $E$-geometry of the starting oxindole could positively affect the efficiency and selectivity of the reaction, we continued our survey using pure $(E)$-1a.

Lowering the reaction temperature to $-15^{\circ} \mathrm{C}$ (entry 4) resulted in the formation of product 3aa in a highly improved $Z / E$ ratio (10.6:1) without loss of efficiency ( $80 \%$ yield), albeit requiring longer reaction time (16 h). $N$-Boc protected oxindole $(E)-\mathbf{1 b}$ also proved a viable substrate under these conditions (entry 5), and the expected product $\mathbf{3 b a}$ could be obtained in a good $73 \%$ combined yield, as an 8.3:1 Z/E mixture of isomers in an enantiopure format.

Subsequent optimization on this $N$-Boc-protected substrate $(E)-\mathbf{1 b}$ revealed that an improved geometric selectivity in the product $\mathbf{3 b a}$ could be achieved using cinchonine-derived thiourea catalyst II (entry 6, 11.5:1 Z/E); decreasing instead the catalyst loading to $5 \mathrm{~mol} \%$ or $3 \mathrm{~mol} \%$ (entries 7 and 8 ) resulted in a slight erosion of both efficiency and $Z / E$ selectivity, and required longer reaction times $(24 \mathrm{~h})$. Of note, the reaction resulted viable also with a catalyst loading up to $1 \mathrm{~mol} \%$, though a substantial decrease of the reaction efficiency rendered these conditions less practical. In this case compound $\mathbf{3 b a}$ was produced in a in a poor $33 \%$ yield while maintaining high $Z / E$ selectivity (9:1) and excellent enantiocontrol ( $>99 \%$ ee) even at $40{ }^{\circ} \mathrm{C}$ (entry 9).

Willing to improve the reaction performance even more, we observed that longer reaction times associated with higher catalyst loadings produced a detrimental effect on the overall efficiency and selectivity of the process. We ascribed this behavior to an unproductive catalyst-mediated isomerization of $(E)-\mathbf{1}$ to the "slower" (Z)-1 isomer. ${ }^{[12]}$ Also, envisaging that similar isomerization equilibria might be operative on final adducts $(Z)-\mathbf{3}$, we reasoned that longer reaction times would consequently end-up with lower $Z / E$ ratios. To shorten reaction times while maintaining useful levels of "active" $(E)-\mathbf{1 b}$ in solution, we performed the reaction at room temperature, with $3 \mathrm{~mol} \%$ of II, and a slight excess of $(E)-\mathbf{1 b}$ instead of $\mathbf{2 a}(1.5 / 1 \mathbf{1 b} / \mathbf{2 a}$ molar ratio). This choice proved to be successful, and almost enantiopure (Z)-3ba could be obtained after $16 \mathrm{~h}$ in an almost quantitative yield (98\%), and 13:1 Z/E ratio (entry 10).

To complete the survey, under the optimized reaction conditions, the pseudo-enantiomer quinidinederived thiourea III (9-epi-QDT, $3 \mathrm{~mol} \%$ ) proved to be less efficient in promoting the title reaction, yielding the corresponding enantiomer ent-(Z)-3ba with only a $50 \%$ combined yield in a $10: 1 \mathrm{Z} / E$ ratio and $>99 \%$ ee (entry 11). With this catalyst, a significant improvement was achieved using $10 \mathrm{~mol} \%$ loading (70\% yield), albeit with a slight decrease in selectivity $(8: 1 \mathrm{Z} / \mathrm{E}$, entry 12$){ }^{[13]}$

\section{Reaction Scope and Limitations}

With the optimal reaction conditions at hand (Table 1 , entry 10), a careful insight into scope and limitations of this direct VMcR was investigated. We started by evaluating the role exerted by the nitrogen appendage $\mathrm{R}^{1}$ on the reaction outcome (Table 2). Under the optimized reaction conditions, Mocprotected oxindole $(E)$-1a confirmed to be viable, yielding nitroalkylidene adduct 3aa in a very good $90 \%$ isolated yield, a 11:1 Z/E ratio and an almost total syn/anti diastereocontrol (>20:1 3', $4^{\prime}$-syn/anti dr) and enantiocontrol $(>99 \%$ ee $)$.

Table 2. Substrate scope of the asymmetric VMcR: variation of $R^{1}$ and $R^{2}$ moieties. ${ }^{[a]}$

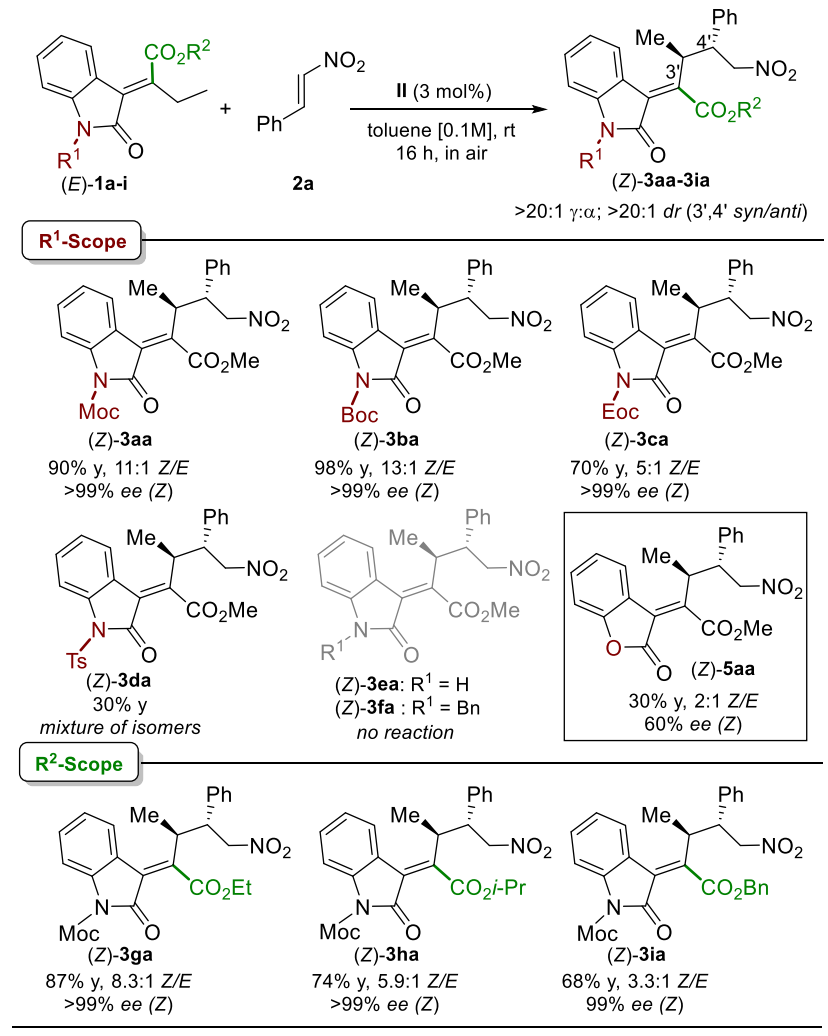

[a] Unless otherwise noted, all reactions were carried out on a $0.2 \mathrm{mmol}$ scale of $\mathbf{2 a}[0.1 \mathrm{M}]$ using $\mathbf{1} / \mathbf{2} \mathbf{a}$ (1.5:1 molar ratio), II $(3 \mathrm{~mol} \%)$ in toluene at r.t. in air, for $16 \mathrm{~h}$. Yields (y) refer to isolated combined yields. $Z / E$ ratio values were determined by ${ }^{1} \mathrm{H}$ NMR of the crude. $e e \%$ were determined by chiral HPLC analysis (see the Supporting Information for details).

Switching to ethyl carbamate derivative $(E)-\mathbf{1 c}$, a slightly inferior performance was recorded, in both efficiency (70\% yield) and geometry control (5:1 Z/E). Furthermore, the presence of a multidentate moiety 
such as the tosyl group in (E)-1d resulted highly detrimental for the reaction, affording a not-wellidentified mixture of isomeric products.

Finally, protecting group-free oxindole $(E)-1 \mathbf{e}$ and benzyl-protected derivative $(E)$-1f proved inert toward 2a even under higher temperatures and with higher catalyst loadings. Interestingly, treating oxygenated 3alkylidene coumaranone analogue ( $Z$ )-4a with 2a under the same reaction conditions (Table 2, framed compound), gave the corresponding adduct 5aa in a very modest $30 \%$ yield with poor stereocontrol (2:1 $Z / E$ ratio, $60 \%$ ee for the $Z$-isomer).

Table 3. Substrate scope of the asymmetric VMcR: variation of $R^{3}, R^{4}$, and $R^{5}$ moieties. ${ }^{[a]}$

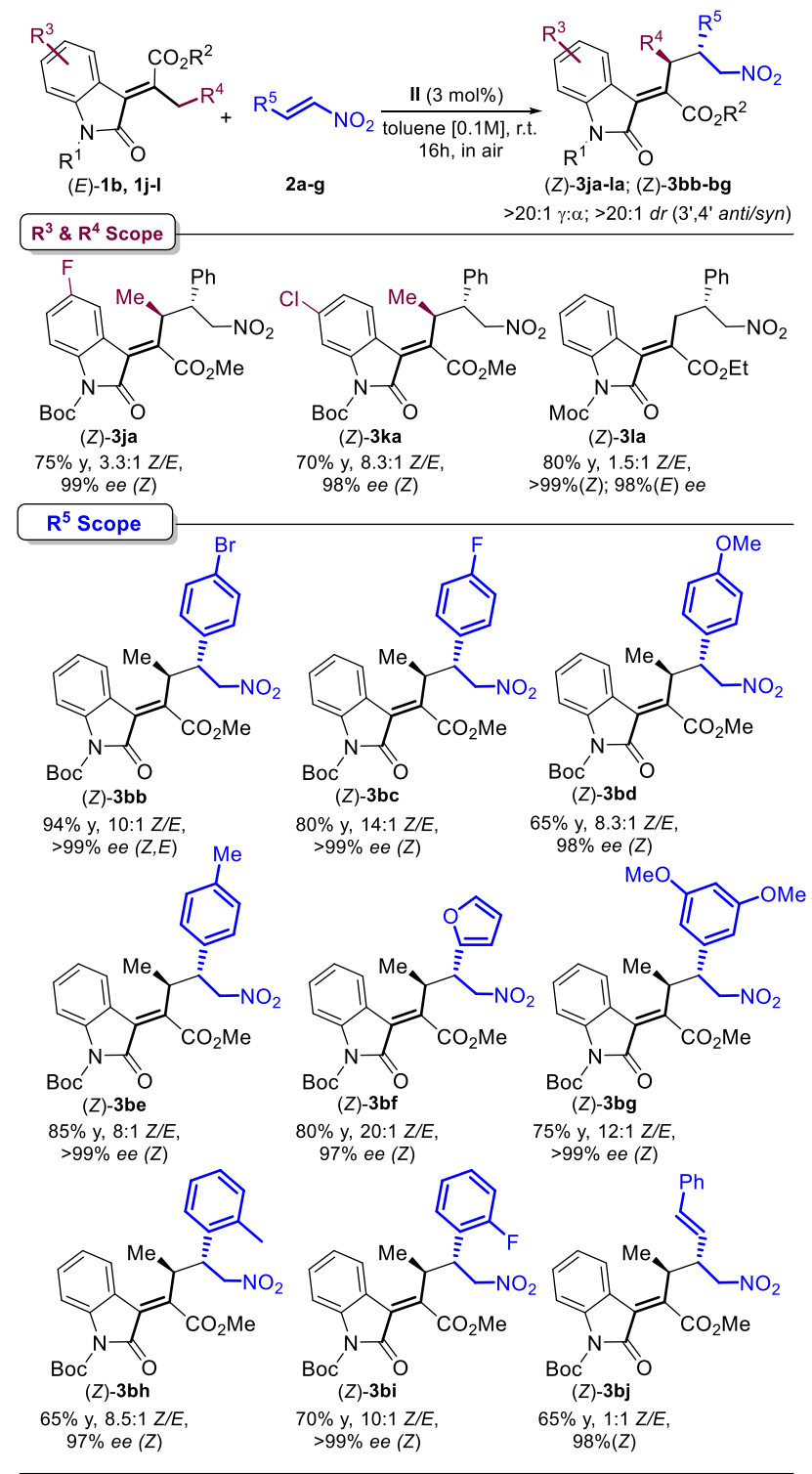

[a] Unless otherwise noted, all reactions were carried out on a $0.2 \mathrm{mmol}$ scale of 2 [0.1M] using $\mathbf{1} / \mathbf{2}$ (1.5:1 molar ratio), II $(3 \mathrm{~mol} \%)$ in toluene at r.t. in air, for $16 \mathrm{~h}$. Yields (y) refer to isolated combined yields. $Z / E$ ratio values were determined by ${ }^{1} \mathrm{H}$ NMR of the crude. $e e \%$ were determined by chiral HPLC analysis (see the Supporting Information for details).
These results confirm that the presence of a carbamate moiety installed at the oxindole nitrogen is pivotal for both the activation of pronucleophilic $(E)$ 1 and the stereocontrol of the whole process exerted by the dual cinchona-thiourea catalyst (vide infra)..$^{[4,14]}$

We next focused the attention on the ester appendage; in particular, the effects of ethyl- (1g), isopropyl- (1h), benzyl- (1i), and tert-butyl-ester derivatives were compared to the methyl ester analogue 1a in terms of reaction efficiency and selectivity (Table 2, bottom). Of note, with the exception of the bulky tert-butyl ester derivative (not shown), which proved to be totally unreactive, the other oxindole scaffolds worked quite well, following a trend in which both yields and $Z / E$ selectivity tended to worsen by the order methyl $>$ ethyl $>$ isopropyl $>$ benzyl (Table 2, bottom).

This fact prompted us to conclude that the alkoxycarbonyl group moiety of the starting alkylidene - a peculiar structural motif of the title oxindoles - plays an important role in governing the reaction fate and regulating the geometry control of the products. Indeed, as anticipated in the premises of the work, it may function as a cardinal point of interaction with the catalyst concurring in the stabilization of the s-trans conformation of the in situformed dienolate species (vide infra).

Continuing the screening of the pronucleophilic substrates, evaluation of 5-fluoro- and 6-chlorooxindole derivatives $1 \mathbf{j}$ and $\mathbf{1 k}$ was performed, giving the corresponding adducts $\mathbf{3 j a}$ and $\mathbf{3 k a}$ in good yields and modest-to-good stereoselectivities (Table 3, top). Interestingly, non-prostereogenic pyruvate-derivative 11 proved a viable substrate under the optimized reaction conditions, consigning adduct 3la in a good $80 \%$ yield and excellent enantioselectivity, albeit with a complete loss of $Z / E$ selectivity, a fact that we ascribed to an increased rate of $Z / E$ isomerization of the product operated by the catalyst during the reaction course. Several nitroalkene acceptors were also investigated (Table 3, bottom). Irrespective of the electronic and steric demand of the aromatic ring within nitroalkenes $\mathbf{2 b}-\mathbf{i}$, all reactions worked efficiently, and the corresponding vinylogous adducts 3bb-3bi were isolated in good yields (65-98\%), good $Z / E$ ratios (8:1-20:1), and excellent enantioselectivity $(97->99 \% e e)$. Interestingly, the reaction between $(E)-$ $\mathbf{1 b}$ and extended diene $\mathbf{1 j}$ afforded a 1:1 $Z / E$ separable mixture of the sole $\beta$-adduct $3 \mathbf{b j}$, in an acceptable $65 \%$ yield and almost complete enantiocontrol.

Also, 4-bromo nitrostyrene $\mathbf{2 b}$ was successfully tested on a tenth-fold scale $(1.5 \mathrm{mmol}$, Scheme 3, eq. a), confirming the high efficiency and selectivity of the optimized process from a preparative point of view; indeed, enantiopure $(Z)-\mathbf{3 b b}$ could be isolated from a 10:1 $Z / E$ mixture in a $89 \%$ yield. Moreover, compound (Z)-3bb turned out particularly useful for the determination of the absolute configuration and double bond geometry of nitroalkylidene adducts 3 . As shown in Scheme 3 (bottom), the absolute $\left(3^{\prime} S, 4^{\prime} R\right)$-configuration of compound $(Z)$-3bb was unambiguously determined by $\mathrm{X}$-ray structure 
analysis. Therefore, the absolute configuration of all other major Z-configured nitroalkylidene adducts $\mathbf{3}$ was assigned in analogy, by assuming a similar reaction behaviour. ${ }^{[15]}$

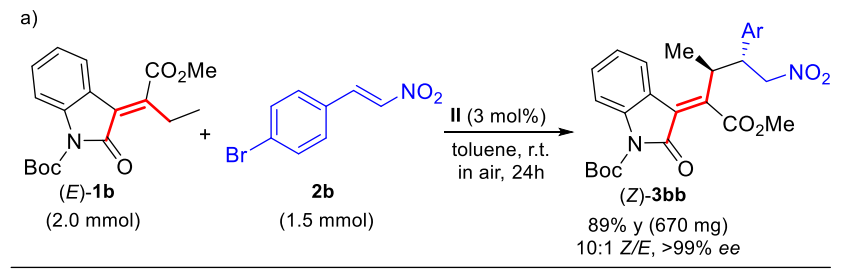

b)

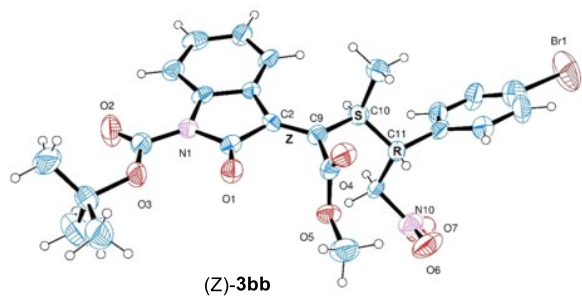

Scheme 3. Preparative scale synthesis of enantiopure (Z)3bb (a); X-ray crystal structure of (Z)-3bb (b).

Regarding less reactive aliphatic nitroalkene acceptors, several candidates including cyclohexyl-, isopropyl-, and butyl-nitroalkenes were tested under the optimized or even harsher reaction conditions, without success. As an exception, 4phenylnitrobutene (2k) smoothly reacted with oxindole $(E)-\mathbf{1 b}$ at room temperature (10 mol\% catalyst loading), affording a 3:1 diastereomeric mixture of racemic 6bk (Scheme 4) resulting from a nonvinylogous $\alpha$-attack ( $8: 1 \alpha / \gamma ; 60 \%$ combined yield as a racemate), accompanied by a small amount (20\%) of racemic $(Z)-7$, a tautomeric form of the starting material.

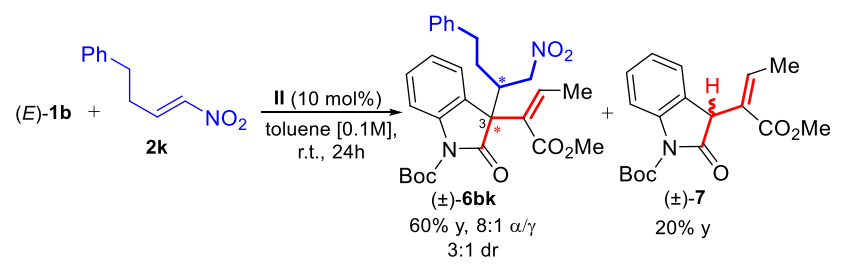

Scheme 4. Organocatalyzed Michael reaction between oxindole $(E)-\mathbf{1 b}$ and aliphatic 4-phenyl-nitrobutene $\mathbf{2 k}$, affording $\alpha$-adduct $( \pm)$-6bk and $\alpha$-tautomer $( \pm)$-7.

An important feature of the present asymmetric $\mathrm{VMcR}$ is that it provides chiral multifunctional products in which the exocyclic C3-C2' double bond of the starting (alkoxy)alkylidene oxindole is preserved (and geometrically inverted), providing opportunities for further useful transformations. In this context, we envisaged that, upon chemoselective reduction of the terminal nitro group to an amine, an unprecedented merger oxindole-proline structure of type $\mathbf{8}$ could be accessed (Scheme 5, eq. 1), via intramolecular aza-Michael closure of the amine on the alkylidene olefin.

Pleasingly, treating enantiopure (Z)-3bb with $\mathrm{Zn}$ /ammonium formate couple in methanol, the quaternary proline methyl ester derivative (-)-8bb was obtained in a good $65 \%$ yield as a separable $4: 1$ mixture of epimers at C3, as certified by extensive 1D and 2D NMR studies (see the Supporting Information for details). ${ }^{[16]}$

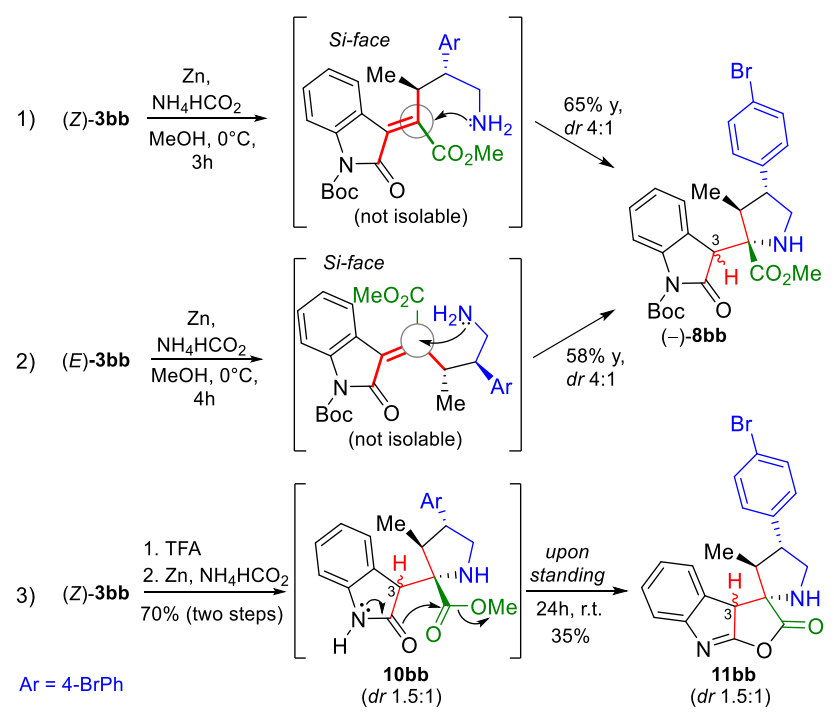

Scheme 5. Transformations of 4-bromo-derivatives $(Z)$ $\mathbf{3 b b}$ and $(E)-\mathbf{3 b b}$ to indolyl-proline $\mathbf{8 b b}$ and spirocyclic furoindolone $\mathbf{1 1 b b}$.

As a fine stereochemistry joke, the same oxindoleproline product $\mathbf{8 b}$ was afforded by starting from the geometric isomer $(E)$-3bb under the same reaction conditions, via the attack of the amine intermediate on the $\mathrm{Si}$-face of the exocyclic C2', as detailed in Scheme 5 (eq. 2). When the same reductive cyclization was performed on deprotected oxindole from $(Z)-\mathbf{3 b} \mathbf{b}$, an unexpected yet quite interesting result was obtained. In fact, as shown in Scheme 5 (eq. 3), treating ( $Z$ )-3bb with trifluoroacetic acid (giving deprotected oxindole 9bb, not shown) followed by $\mathrm{Zn}$ /formate reduction gave the expected $N$-deprotected oxindole-proline 10bb, which spontaneously converted into furoindolone spirocycle $\mathbf{1 1 b b}$ as an inseparable 1.5:1 diastereoisomeric mixture. ${ }^{[17]}$

\section{Mechanistic Rationale and DFT Calculations}

Capitalizing on previous activation models for cinchona-thiourea catalyzed reactions, and based on theoretical calculations for similar transformations, ${ }^{[18,1 \mathrm{a}, 5 \mathrm{c}]}$ a plausible mechanistic pathway is proposed to explain the stereochemical outcome of this asymmetric VMcR. As described in Scheme 6 for the synthesis of (Z)-3aa, we postulate that an initial hydrogen bonding interaction of the catalyst (I or II) with the highly reactive oxindole pronucleophile $(E)$-1a generates complex $\mathbf{F}$ in which the quinuclidine portion of the catalyst is spatially set 
close to the acidic $\gamma$-methylene site positioned in cis to the lactam carbonyl C2. Subsequent deprotonation of this $\gamma$-site generates a dienolate $(Z)$-1a' that mainly reacts with nitrostyrene $\mathbf{2 a}$ in a stabilized s-trans conformation after rotation of the ester moiety along the $\mathrm{C} 3-\mathrm{C} 2$ ' bond.

The catalyst ability to stabilize the active $s$-trans conformation of 1a' may be due to the formation of $\mathrm{H}$ bonding network involving the protonated quinuclidine, the oxy-anion at $\mathrm{C} 2$, and the ester moiety, as depicted in complex G. ${ }^{[19]}$ According to this proposal, the observed inverse relationship between the hindrance of the ester substituent on the pronucleophile and the $Z / E$ selectivity would be explained. More hindered esters might hamper the stabilizing H-bonding, allowing a higher degree of rotation along the $\mathrm{C} 3-\mathrm{C} 2$ ' bond.

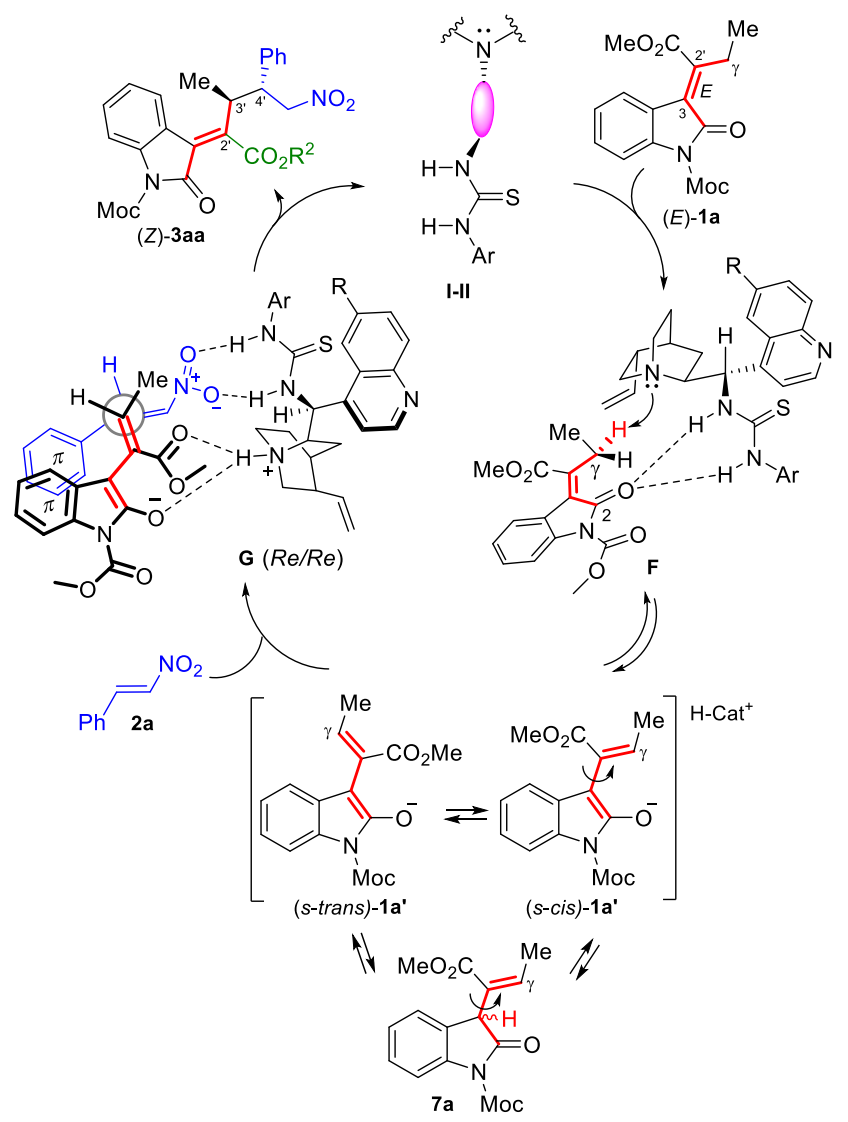

Scheme 6. Proposed mechanism pathway for the asymmetric VMcR between 3-(alkoxycarbonyl)propylidene oxindole $(E)-\mathbf{1 a}$ and nitrostyrene $\mathbf{2 a}$ promoted by catalyst I or II.

The high degree of stereoselectivity observed in the VMcR may thus be ascribed to the formation of the tight transition state $\mathbf{G}$ (Scheme 6) in which the interaction of the Re face of the s-trans dienolate 1a' with the $R e$ face of the activated nitroalkene is perfectly orchestrated by the dual catalyst, to afford $\left(3 ' S, 4^{\prime} R\right)$-configured $(Z)$-3aa almost exclusively. In addition, the synclinal approach as in $\mathbf{G}$ may be favoured by weak $\pi-\pi$ interactions between the overlapping indole and the nitroalkene aromatic rings, an issue that may also account for the inertness observed for aliphatic nitroalkenes.

To support the proposed mechanistic rationale, we conducted some preliminary DFT calculations relative to $i$ ) the deprotonation step of oxindole $(E)$-1a and $i$ ) the addition reaction catalyzed by 9-epi-CDT (II) with $(E)$-2a, giving product 3aa (Table 2). ${ }^{[20,21]}$ Concerning the deprotonation step (complex $\mathbf{F}$, Scheme 6), two transition states, TS_A and TS_B (Figure 2), relative to the deprotonation of $(E)-\mathbf{1 a}$ in complex with the organocatalyst II, were identified giving the corresponding dienolates $(Z)-\mathbf{1} \mathbf{a}^{\prime}$ and $(E)$ $\mathbf{1} \mathbf{a}^{\prime}$, respectively.

Transition state TS_A was predicted to be more stable than TS_B, using both the $6-31 \mathrm{G}(\mathrm{d})$ basis set in the gas phase $\left(\Delta \Delta \mathrm{G}^{+}=4.62 \mathrm{Kcal} / \mathrm{mol}\right)$ and the triple- $\zeta$ def2-TZVPP basis set in toluene $\left(\Delta \Delta \mathrm{G}^{\ddagger}=4.58\right.$ $\mathrm{Kcal} / \mathrm{mol}){ }^{[22]}$

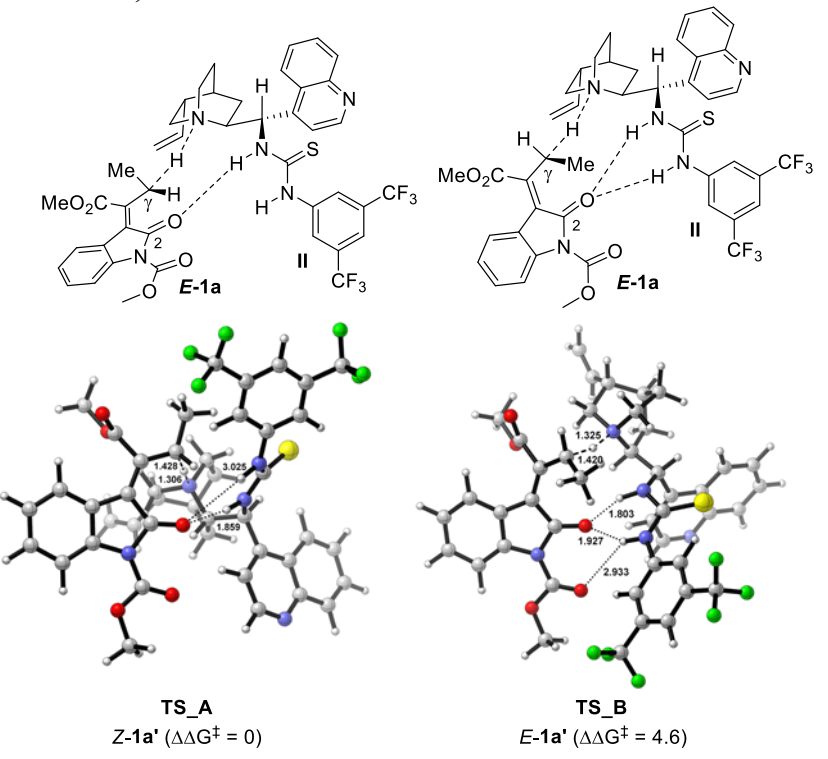

Figure 2. Transition states TS_A and TS_B relative to the deprotonation of $(E)$-1a with catalyst II. M06-2X/def2TZVPP-IEFPCM(toluene)//M06-2X/6-31G(d); energies in $\mathrm{Kcal} / \mathrm{mol}$.

Thus, only the Z-configured dienolate 1a' was selected for exploring the addition reaction step to nitrostyrene $(E)-2 a$. Considering the approach of the s-cis and s-trans limit conformations of (Z)-1a', two transitions states TS_C and TS_D (Figure 3) were identified for the two possible $\operatorname{Re} / \operatorname{Re}$ approaches leading to the known absolute $\left(3^{\prime} S, 4^{\prime} R\right)$ configuration of the products. Once again, using both the less demanding 6-31G(d) basis set in the gas phase $\left(\Delta \Delta \mathrm{G}^{\ddagger}\right.$ $=7.8 \mathrm{Kcal} / \mathrm{mol})$ and def2-TZVPP basis set in toluene $\left(\Delta \Delta \mathrm{G}^{\ddagger}=7.9 \mathrm{Kcal} / \mathrm{mol}\right)$, the transition state involving (Z)-(s-trans)-1a' (TS_C, Figure 3, left) was predicted to be considerably more stable than the (Z)-(s-cis)-1a' complex (TS_D, Figure 3, right). This difference can be explained by considering that in TS_D: $i$ ) no 
stabilizing hydrogen-bond interactions are possible between the thiourea moiety or the protonated tertiary amine and the partially negative charged oxindole $\mathrm{C} 2$ oxygen, and $i$ ) the substituents around the forming C3'-C4' bond are arranged in an almost eclipsed conformation.
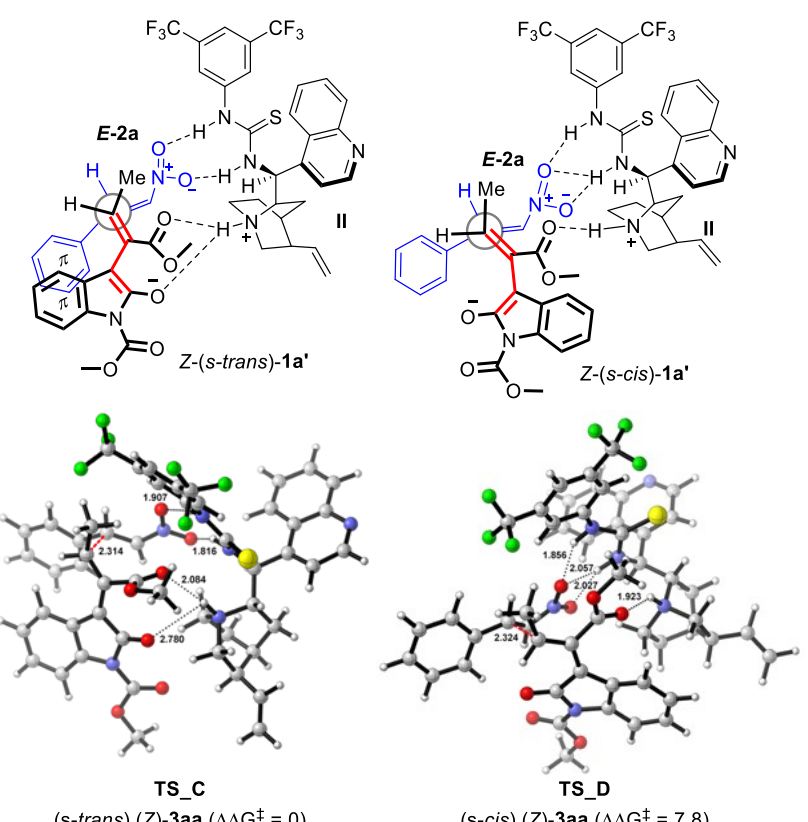

Figure 3. Transition states TS_C and TS_D relative to the

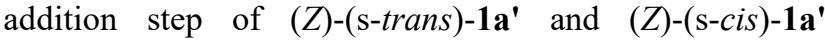
complexes with catalyst II and nitroolefin $(E)-\mathbf{2 a}$; the approach of (Z)-(s-cis)-1a' and (E)-2a corresponds to an almost eclipsed conformation, but was reported as staggered for the sake of clarity. M06-2X/def2-TZVPPIEFPCM(toluene)//M06-2X/6-31G(d); energies in $\mathrm{Kcal} / \mathrm{mol}$

In both TSs, the dual activation mode of the catalyst was in accordance to the one proposed by Takemoto, ${ }^{[18 a]}$ in which the thiourea activates the electrophile (2a) and the protonated tertiary amine activates the nucleophile (1/a') by hydrogen bonding. It is interesting to note that in both cases the ester group at $C \beta$ is actively involved in the formation of stabilizing hydrogen-bond interactions with the protonated quinuclidine of catalyst II, thus playing an active role in determining the stereoselectivity of the process.

\section{Conclusion}

In summary, we exploited the $d^{4}$-reactivity of in situ generated prostereogenic, multidentate and captodative dienolates derived by $\mathrm{C}-\gamma$ enolization of (E)-3-(alkoxycarbonyl-2-alkyliden)-2-oxindoles in direct, enantioselective, vinylogous Michael addition to nitroolefins nicely orchestrated by chiral, bifunctional cinchona-thiourea organocatalysts.
This reaction provided valuable and highly enantioenriched nitroalkylidene oxindole adducts in good isolated yields, complete $\gamma$-site and syn/anti diastereoselectivity, and showed tolerance for a wide range of functionality. Of note, an unprecedented $Z$ selective outcome was observed in many cases. In this context, experimental and DFT data highlight the crucial role exerted by the distinctive alkoxycarbonyl appendage in the stabilization of the active $s$-trans conformation of the in situ-formed dienolate species, via peculiar noncovalent interactions with the catalyst.

Finally, the synthetic versatility of the products was demonstrated by a couple of representative transformations leading to a quaternary oxyndolylproline analogue and a spirocyclic furoindolone structure.

\section{Experimental Section}

General Procedure for the Synthesis of 3(Alkoxycarbonyl-2-Alkyliden)-2-Oxindoles of Type 1

\section{Preparation of $(E)$ and $(Z)-3-(2-M e t h o x y c a r b o n y l-2-$ propylidene)indolin-2-one (1e)}

To a solution of commercial 2-oxindole ( $460 \mathrm{mg}, 3.45$ mmol, 1.0 equiv) in a $1: 1$ mixture of methyl-2-oxobutanoate/MeOH $(10 \mathrm{~mL})$, vigorously stirred at $0{ }^{\circ} \mathrm{C}$, piperidine was added ( $68 \mu \mathrm{l}, 0.69 \mathrm{mmol}, 0.2$ equiv). The resulting solution was stirred at $0{ }^{\circ} \mathrm{C}$ for $3 \mathrm{~h}$, and then warmed to r.t. for further $24 \mathrm{~h}$. The resulting solution was concentrated under vacuum, and the crude was purified by silica gel flash chromatography (gradient mixture from $70: 30$ to $60: 40$ petroleum ether/EtOAc) to yield the corresponding aldol adduct $(830 \mathrm{mg}, 97 \%$ yield) as a $3: 1$ mixture of two diastereoisomers as a white solid. Recrystallization from a 2:1 water/MeOH mixture allowed the separation of the major isomer as a white, amorphous solid.

The previously prepared mixture of aldol adducts $(830$ $\mathrm{mg}, 3.33 \mathrm{mmol}, 1.0$ equiv) was suspended in water $(30 \mathrm{~mL})$ and to the resulting suspension $10 \% \mathrm{HCl}(5 \mathrm{~mL})$ was added dropwise at r.t. The solution was refluxed for $1 \mathrm{~h}$ at $100^{\circ} \mathrm{C}$. The resulting yellow solution was cooled to r.t., then extracted with EtOAc $(3 \times 30 \mathrm{~mL})$ and the combined organic layers were dried with $\mathrm{MgSO}_{4}$ and concentrated in vacuo to yield a yellow-orange resin. The resulting crude was purified by silica gel flash chromatography (65:35 petroleum ether/EtOAc) to yield pure $(Z)-1 \mathrm{e}(371 \mathrm{mg})$ as a yellow-orange solid and pure $(E)-1 \mathrm{e}(167 \mathrm{mg}, 70 \%$ combined yield) as a light yellow solid.

(E)-1e: ${ }^{1} \mathrm{H}$ NMR (400 MHz, chloroform- $d$ ): $\delta 9.10(\mathrm{bs}$, 1H, NH), 7.19-7.25 (m, 2H, H4, H6), 6.96 (dd, $J=7.7,7.7$ $\mathrm{Hz}, 1 \mathrm{H}, \mathrm{H} 5), 6.86$ (bd, $J=7.7 \mathrm{~Hz}, 1 \mathrm{H}, \mathrm{H} 7), 3.98$ (s, 3H, $\left.\mathrm{CO}_{2} \underline{\mathrm{Me}}\right), 3.24$ (q, $\left.J=7.6 \mathrm{~Hz}, 2 \mathrm{H}, \underline{\mathrm{CH}_{2}} \mathrm{CH}_{3}\right), 1.22$ (t, $J=7.6$ $\left.\mathrm{Hz}, 3 \mathrm{H}, \mathrm{CH}_{2} \underline{\mathrm{CH}}_{3}\right) ;{ }^{13} \mathrm{C} \mathrm{NMR}(100 \mathrm{MHz}$, chloroform-d): $\delta 169.9(\mathrm{Cq}), 169.2(\mathrm{Cq}), 146.9(\mathrm{Cq}), 140.5(\mathrm{Cq}), 129.8$ $(\mathrm{CH}), 124.5(\mathrm{Cq}), 122.4(\mathrm{CH}), 122.1(\mathrm{CH}), 121.0(\mathrm{Cq})$, $110.2(\mathrm{CH}), 52.5\left(\mathrm{CH}_{3}, \mathrm{CO}_{2} \mathrm{Me}\right), 22.8\left(\mathrm{CH}_{2}, \mathrm{C} 3{ }^{\prime}\right), 12.2$ $\left(\mathrm{CH}_{3}, \mathrm{C}^{\prime}\right)$; HR-MS: $m / z=232.0960$, calcd. for $\mathrm{C}_{13} \mathrm{H}_{14} \mathrm{NO}_{3}$ : $232.0973[\mathrm{M}+\mathrm{H}]^{+}$.

(Z)-1e: ${ }^{1} \mathrm{H}$ NMR (400 MHz, chloroform- $d$ ): $\delta 9.26$ (bs, $1 \mathrm{H}, \mathrm{NH}), 7.49$ (bd, $J=7.7 \mathrm{~Hz}, 1 \mathrm{H}, \mathrm{H} 4), 7.25$ (ddd, $J=7.7$, 7.7, 1.1 Hz, 1H, H6), 7.02 (ddd, $J=7.7,7.7,0.8 \mathrm{~Hz}, 1 \mathrm{H}$, H5), 6.89 (bd, $J=7.7 \mathrm{~Hz}, 1 \mathrm{H}, \mathrm{H} 7), 3.94$ (s, 3H, $\left.\mathrm{CO}_{2} \mathrm{Me}\right)$, $2.83\left(\mathrm{q}, J=7.6 \mathrm{~Hz}, 2 \mathrm{H}, \underline{\mathrm{CH}_{2}} \mathrm{CH}_{3}\right), 1.31(\mathrm{t}, J=7.6 \mathrm{~Hz}, 3 \mathrm{H}$, 
$\left.\mathrm{CH}_{2} \underline{\mathrm{CH}}_{3}\right) ;{ }^{13} \mathrm{C} \mathrm{NMR}(75 \mathrm{MHz}$, chloroform- $d): \delta 170.0(\mathrm{Cq}$ $\mathrm{C} 2), 168.6\left(\mathrm{Cq}, \mathrm{CO}_{2} \mathrm{Me}\right), 146.2(\mathrm{Cq}, \mathrm{C} 7 \mathrm{a}), 141.8(\mathrm{Cq}, \mathrm{C} 3)$, $130.1(\mathrm{CH}), 125.4\left(\mathrm{Cq}, \mathrm{C}^{\prime}\right), 124.4(\mathrm{CH}), 122.6(\mathrm{CH}), 121.9$ (Cq, C3a), $110.8(\mathrm{CH}, \mathrm{C} 7), 52.8\left(\mathrm{CH}_{3}, \mathrm{CO}_{2} \mathrm{Me}\right), 25.1\left(\mathrm{CH}_{2}\right.$, C3'), $11.3\left(\mathrm{CH}_{3}, \mathrm{C}^{\prime}\right)$; HR-MS: $m / z=232.0957$, calcd. For $\mathrm{C}_{13} \mathrm{H}_{14} \mathrm{NO}_{3}: 232.0973[\mathrm{M}+\mathrm{H}]^{+}$.

\section{Preparation of (E)-1-(tert-Butoxycarbonyl)-3-(2- methoxycarbonyl-2-propylidene)indolin-2-one $(E)-1 b$}

To a solution of deprotected oxindole $(E)-1 e$ ( $150 \mathrm{mg}, 0.64$ mmol, 1.0 equiv) in $\mathrm{CH}_{3} \mathrm{CN}(10 \mathrm{~mL})$, kept under stirring at $0{ }^{\circ} \mathrm{C}$ (ice bath) under nitrogen atmosphere, di-tert-butyl dicarbonate (Boc) $)_{2} \mathrm{O}$ (209 $\mathrm{mg}, 0.96 \mathrm{mmol}, 1.5$ equiv) and DMAP ( $7.8 \mathrm{mg}, 0.06 \mathrm{mmol}, 0.1$ equiv) were sequentially added and the solution turned from yellow to light yellow. After $30 \mathrm{~min}$, an aqueous solution of $\mathrm{CuSO}_{4}(0.5 \mathrm{~N})$ was added dropwise to the reaction mixture. The crude was extracted with EtOAc $(3 \times 10 \mathrm{~mL})$ and the combined organic layers were dried with $\mathrm{MgSO}_{4}$ and concentrated in vacuo to yield a yellow oil. The resulting crude was purified by silica gel flash chromatography $(95: 5$ petroleum ether/EtOAc) to yield $170 \mathrm{mg}$ of pure $(E)-\mathbf{1 b}(80 \%$ isolated yield) as a yellow resin.

$(E)-1 \mathbf{b}:{ }^{1} \mathrm{H}$ NMR $(400 \mathrm{MHz}$, chloroform- $d)$ : $\delta 7.87(\mathrm{~d}$, $J=8.2 \mathrm{~Hz}, 1 \mathrm{H}, \mathrm{H} 7), 7.33$ (dd, $J=7.8,7.8 \mathrm{~Hz}, 1 \mathrm{H}, \mathrm{H} 6), 7.22$ (bd, $J=7.8 \mathrm{~Hz}, 1 \mathrm{H}, \mathrm{H} 4), 7.10$ (ddd, $J=7.8,7.8,1.0 \mathrm{~Hz}, 1 \mathrm{H}$, $\mathrm{H} 5), 3.98$ (s, 3H, $\mathrm{CO}_{2} \mathrm{Me}$ ), 3.19 (q, J=7.6 Hz, $2 \mathrm{H}, \underline{\mathrm{CH}}_{2} \mathrm{CH}_{3}$ ), 1.67 ( $\mathrm{s}, 9 \mathrm{H}, t-\mathrm{Bu}, \mathrm{Boc}), 1.22$ (t, $\left.J=7.5 \mathrm{~Hz}, 3 \mathrm{H}, \mathrm{CH}_{2} \mathrm{CH}_{3}\right)$; ${ }^{13} \mathrm{C}$ NMR (100 MHz, chloroform- $\left.d\right)$ : $\delta 169.4(\mathrm{Cq}, \mathrm{C} 2)$, $165.5\left(\mathrm{Cq}, \mathrm{CO}_{2} \mathrm{Me}\right), 149.4(\mathrm{Cq}, \mathrm{Boc}), 147.8(\mathrm{Cq}, \mathrm{C} 3$ or C7a), 139.1 (Cq, C7a, or C3), 130.1 (CH, C4), 124.2 (CH, C6), 123.0 (Cq, C2'), 121.9 (CH, C5), 120.9 (Cq, C3a), 115.2 $(\mathrm{CH}, \mathrm{C} 7), 84.6(\mathrm{Cq}, t-\mathrm{Bu}, \mathrm{Boc}), 52.7\left(\mathrm{CH}_{3}, \mathrm{CO}_{2} \mathrm{Me}\right), 28.3$ (3C, $\mathrm{Me}, t-\mathrm{Bu}, \mathrm{Boc}), 23.6\left(\mathrm{CH}_{2}, \mathrm{C}^{\prime}\right), 12.2\left(\mathrm{CH}_{3}, \mathrm{C} 4{ }^{\prime}\right)$; HRMS: $m / z=332.1484$, calcd. for $\mathrm{C}_{18} \mathrm{H}_{21} \mathrm{NO}_{5}: 332.1498$ $[\mathrm{M}+\mathrm{H}]^{+}$.

General Procedure for the Synthesis of Vinylogous Michael Adducts of Type 3

\section{Preparation of $(Z)-\left(3^{\prime} \quad S, 4^{\prime} \quad R\right)-1-($ tert-}

Butoxycarbonyl)-3-(2-methoxycarbonyl-3-methyl-5nitro-4-phenyl pentan-2-ylidene)-indolin-2-one (3ba)

To a solution of oxindole $(E)-\mathbf{1 b}(100 \mathrm{mg}, 0.3 \mathrm{mmol}, 1.5$ equiv) in toluene $(2 \mathrm{~mL})$ at r.t., trans- $\beta$-nitrostyrene $\mathbf{2 a}(30$ $\mathrm{mg}, 0.2 \mathrm{mmol}, 1.0$ equiv) and the thiourea-catalyst II (3.4 $\mathrm{mg}, 0.006 \mathrm{mmol}, 0.03$ equiv) were added in one portion. The reaction was kept under vigorous stirring at r.t. and monitored by TLC. After $16 \mathrm{~h}$, the resulting solution was concentrated in vacuum and the crude was purified by silica gel flash chromatography (elution by gradient from $95 / 5$ to $80 / 20$ petroleum ether/EtOAc) to yield pure $(Z)$-3ba $(99$ $\mathrm{mg})$ as a light yellow resin and $(E)-3$ ba $(6.7 \mathrm{mg}, 98 \%$ combined yield) as a pink-yellow resin. The $d r(Z / E)$ of the reaction was determined to be $13: 1$ by ${ }^{1} \mathrm{H}$ NMR analysis of the crude reaction mixture.

(Z)-3ba: ${ }^{1} \mathrm{H}$ NMR (400 MHz, chloroform- $d$ ): $\delta 7.98$ (bd, $J=8.2 \mathrm{~Hz}, 1 \mathrm{H}, \mathrm{H} 7), 7.72$ (bd, $J=7.8 \mathrm{~Hz}, 1 \mathrm{H}, \mathrm{H} 4), 7.42$ (m, 3H, H6, Ph), 7.34 (m, 1H, Ph), 7.28 (m, 3H, H5, Ph), $5.02(\mathrm{dd}, J=12.8,3.7 \mathrm{~Hz}, 1 \mathrm{H}, \mathrm{H} 5 \mathrm{\prime a}), 4.62$ (dd, $J=12.8$, $\left.11.3 \mathrm{~Hz}, 1 \mathrm{H}, \mathrm{H} 5{ }^{\prime} \mathrm{b}\right), 4.04$ (s, 3H, $\mathrm{CO}_{2} \mathrm{Me}$ ), 3.78 (dq, $J=11.3$, $6.6 \mathrm{~Hz}, 1 \mathrm{H}, \mathrm{H} 3$ '), 3.57 (ddd, $J=11.3,11.3,3.0 \mathrm{~Hz}, 1 \mathrm{H}, \mathrm{H} 4{ }^{\prime}$ ), $1.66(\mathrm{~s}, 9 \mathrm{H}, t-\mathrm{Bu}, \mathrm{Boc}), 1.10(\mathrm{~d}, J=6.6 \mathrm{~Hz}, 3 \mathrm{H}, \mathrm{Me}) ;{ }^{13} \mathrm{C}$ NMR (100 MHz, chloroform- $d$ ): $\delta 167.7$ (Cq, C2), 164.0 $\left(\mathrm{Cq}, \mathrm{CO}_{2} \mathrm{Me}\right), 148.9(\mathrm{Cq}, \mathrm{Boc}), 146.5(\mathrm{Cq}, \mathrm{C} 3$ or $\mathrm{C} 7 \mathrm{a})$, $140.9(\mathrm{Cq}, \mathrm{C} 7 \mathrm{a}$ or $\mathrm{C} 3), 137.5(\mathrm{Cq}, \mathrm{Ph}), 131.1(\mathrm{CH}, \mathrm{C} 6)$, 129.4 (2C, CH, Ph), $128.5(\mathrm{CH}, \mathrm{Ph}), 128.2$ (2C, CH, Ph), 125.4 (Cq, C2), 124.7 (CH, C5), 123.7 (CH, C4), 120.7 (Cq,
C3a), 116.0 (CH, C7), 85.1 (Cq, $t$-Bu, Boc), $79.1\left(\mathrm{CH}_{2}, \mathrm{C} 5\right)$, $53.2\left(\mathrm{CH}_{3}, \mathrm{CO}_{2} \mathrm{Me}\right), 48.4(\mathrm{CH}, \mathrm{C} 4), 38.1(\mathrm{CH}, \mathrm{C} 3), 28.2$ (3C, $\mathrm{CH}_{3}, t$-Bu, Boc), $17.3\left(\mathrm{CH}_{3}, \mathrm{Me}\right)$; HR-MS: $m / z=$ 481.1961, calcd. for $\mathrm{C}_{26} \mathrm{H}_{28} \mathrm{~N}_{2} \mathrm{O}_{7}$ : $481.1975[\mathrm{M}+\mathrm{H}]^{+}$; $[\alpha]_{\mathrm{D}}^{20}=+124.0\left(\mathrm{c} 1.0, \mathrm{CHCl}_{3}\right)$; chiral HPLC (Lux Amylose1, 90/10 Hexane/Ethanol, $1.0 \mathrm{~mL} / \mathrm{min}, 254 \mathrm{~nm}$ ): $\mathrm{R} t 5.84 \mathrm{~min}$ (minor), $6.43 \mathrm{~min}$ (major) (99.9:0.1 er).

\section{Crystal Data}

CCDC 1561942 contains the supplementary crystallographic data for $(Z)-3 \mathbf{b b}$. These data can be obtained free of charge from The Cambridge Crystallographic Data Centre via www.ccdc.cam.ac.uk/data_request/cif.

\section{Supporting Information}

All synthetic procedures, characterization data, DFT calculations, copies of NMR spectra, and chiral HPLC chromatograms are presented in the Supporting Information

\section{Acknowledgements}

We thank the University of Parma for funding. Thanks are due to Centro Interdipartimentale Misure "G. Casnati" (University of Parma) for instrumental facilities.

[1] a) Stereoselective Organocatalysis: Bond Formation Methodologies and Activation Modes; 1st Ed. (Ed.: R. Rios Torres), John Wiley \& Sons, Inc., New Jersey 2013; b) A. Berkessel, H. Gröger, Asymmetric Organocatalysis: From Biomimetic Concepts to Applications in Asymmetric Synthesis, Wiley-VCH, Weinheim, 2005. For recent reviews on the exploitation of organocatalysis in medicinal chemistry and industry see: c) I. R. Shaikh, Journal of Catalysts 2014, Article ID. 402860; d) A. Ricci, ISRN Org. Chem. collection 2014, Article ID 531695; e) J. Alemà, S. Cabrera, Chem. Soc. Rev. 2013, 42, 774-793.

[2] a) Y. Wang, K. L. Milkiewicz, M. L. Kaufman, L. H. Nelson, G. Landmesser, D. V. Levy, S. P. Allwein, M. A. Christie, M. A. Olsen, C. J. Neville, K. Muthukumaran, Org. Process. Res. Dev. 2017, 21, 408413, and references therein. For selected books and reviews on bifunctional Cinchona alkaloid-thiourea catalysts see: b) Cinchona Alkaloids in Synthesis and Catalysis:Ligands, Immobilization and Organocatalysis, (Ed.: C. E. Song), Wiley-VCH, Weinheim, 2009; c) Y. Takemoto, Chem. Pharm. Bull. 2010, 58, 593-560; d) Z. Zhang, P. R. Schreiner, Chem. Soc. Rev. 2009, 38, 1187-1198; e) S. J. Connon, Chem. Commun. 2008, 2499-2510.

[3] a) L. Battistini, C. Curti, G. Rassu, A. Sartori, F. Zanardi, Synthesis 2017, 2297-2336; b) G. Casiraghi, L. Battistini, C. Curti, G. Rassu, F. Zanardi, Chem. Rev. 2011, 111, 3076-3154; c) C. Schneider, F. Abels, Org. Biomol. Chem. 2014, 12, 3531-3543; d) H. B. Hepburn, L. Dell'Amico, P. Melchiorre, Chem. Rec. 2016, 16, 1787-1806; e) F. Zanardi, G. Rassu, L. Battistini, C. Curti, A. Sartori, G. Casiraghi, In Targets in Heterocyclic Systems - Chemistry and Properties; O. A. 
Attanasi, D. Spinelli, Società Chimica Italiana: Rome, 2012, 56-89; f) M. Kalesse, Top. Curr. Chem. 2005, 244, 43- 76.

[4] a) C. Curti, G. Rassu, V. Zambrano, L. Pinna, G. Pelosi, A. Sartori, L. Battistini, F. Zanardi, G. Casiraghi, Angew.Chem. Int. Ed. 2012, 51, 6200-6204; Angew. Chem. 2012, 124, 6304-6308; b) G. Rassu, V. Zambrano, L. Pinna, C. Curti, L. Battistini, A. Sartori, G. Pelosi, F. Zanardi, G. Casiraghi, Adv. Synth. Catal. 2013, 355, 1881-1886.

[5] a) Q. Chen, G. Wang, X. Jiang, Z. Xu, L. Lin, R. Wang, Org. Lett. 2014, 16, 1394-1397; b) Y. Zhong, S. Ma, Z. Xu, M. Changa, R. Wang, RSC Adv. 2014, 4, 4993049933; c) N. Di Iorio, P. Righi, S. Ranieri, A. Mazzanti, R. G. Margutta, G. Bencivenni, J. Org. Chem. 2015, 80, 7158-7171; d) X. Xiao, H. Mei, Q. Chen, X. Zhao, L. Lin, X. Liu, X. Feng, Chem. Commun. 2015, 51, 580583; e) Y. Liu, Y. Yang, Y. Huang, X.-H. Xu, F.-L. Qing, Synlett 2015, 26, 67-72; f) J. Feng, X. Li, J.-P. Cheng, Chem. Commun. 2015, 51, 14342-14345; g) J. Feng, X. Li, J.-P. Cheng, J. Org. Chem. 2017, 82, 1412-1419. For other related examples see also: h) H. J. Lee, S. Lee, J. Yu, J. N. Kim, Tetrahedron Letters 2014, 55, 24502454 ; i) C. Zheng, H.-F. Wang, W.-Q. Chen, W.-X. Chen, F.-E. Chen, Asian J. Org. Chem. 2015, 4, 619621 ; j) C. Zheng, W.-X. Chen, F.-E. Chen, Asian J. Org. Chem. 2015, 4, 1044-1046; k) J.-L. Han, C.-H. Chang, Chem. Commun. 2016, 52, 2322-2325; 1) H. Mei, L. Lin, L. Wang, X. Feng, Chem. Commun. 2017, 53, 87638766; m) J. Feng, X. Li, J. Org. Chem. 2017, 82, 7317-7323. For a seminal work on enolizable (alkoxycarbonyl)-alkylidene oxindoles see also: n) G. B. Bennett, R. B. Mason, M. J. Shapiro, J. Org. Chem. 1978, 43, 4383-4385.

[6] Due to varied priority of the different alkene substituents within adducts $\mathbf{D}$, the configuration of the alkylidene olefin may be assigned as either $Z$ or $E$. Independent from the specific CIP designation, however, the spatial relationship between the oxindole carbonyl and the electrophile-functionalized chain is invariably cis.

[7] a) A. Millemaggi, R. J. K. Taylor, Eur. J. Org. Chem. 2010, 4527-4547. For selected references on sunitinib bioactivity see: b) A. Sistla, N. Shenoy, Drug Dev. Ind. Pharm. 2005, 31, 1001-1007; c) D. B. Mendel, A. D. Laird, X. Xin, S. G. Louie, J. G. Christensen, G. Li, R.E. Shrek, T. J. Abrams, T. J. Ngai, L. B. Lee, L. J. Murray, J. Carver, E. Chan, K. G. Moss, J. O. Haznedar, J. Sukbuntherng, R. A. Blake, L. Sun, C. Tang, T. Miller, S. Shirazian, G. McMahon, J. M. Cherrington, Clin. Cancer Res. 2003, 9, 327-337.

[8] A. Cooper, G. A. Meister, Chem. Rev. 1983, 83, 321358

[9] a) W. Raimondi, D. Bonne, J. Rodriguez, Angew. Chem. Int. Ed. 2012, 51, 40-42; Angew. Chem. 2012, 124, 4042. For comprehensive reviews see: b) B. Eftekhari-Sis, M. Zirak, Chem. Rev. 2015, 115, 151-264; c) W. Raimondi, D. Bonne, J. Rodriguez, Chem. Commun. 2012, 48, 6763-6775.
[10] a) A. Alizadeh, F. Bayat, L. Moafi, Curr. Org. Chem. 2017, 21, 1292-1334; b) P. Shanmugam, V. Vaithiyanathan, Tetrahedron 2008, 64, 3322-3330.

[11] The "captodative effect" refers to the effect on stability of a carbon-centered radical by the combined action of electron-withdrawing (capto-) and electron-releasing (dative) substituents attached to the radical center. In this work we apply this concept to dienolates 1 ' featuring a $\mathrm{C}-\gamma$ site that in principle may assume a double connotation as either an electrophilic or nucleophilic site. For a comprehensive review on captodative aminoalkenes see: A. Y. Rulev, Russ. Chem. Rev. 2002, $71,195-221$, and references therein.

[12] Similar cinchona alkaloid-thiourea mediated $Z / E$ isomerizations have been previously observed on nonsymmetric 3-alkylidene pronucleophiles. See Ref. $5 c$.

[13] Based on this result, all ent-( $Z$ )-3 adducts (necessary standard compounds for the evaluation of the $e e \%$ of the corresponding adducts (Z)-3 by chiral HPLC), were usefully prepared by running the reaction under the conditions reported in Table 1, entry 12.

[14] For related works describing the influence of nitrogen appendages on the reactivity and selectivity of several heterocyclic vinylogous and hypervinylogous nucleophiles, see: a) C. Curti, A. Sartori, L. Battistini, N. Brindani, G. Rassu, G. Pelosi, A. Lodola, M. Mor, G. Casiraghi, F. Zanardi, Chem. Eur. J. 2015, 21, 64336442; b) C. Curti, B. Ranieri, L. Battistini, G. Rassu, V. Zambrano, G. Pelosi, G. Casiraghi, F. Zanardi, Adv. Synth. Catal. 2010, 352, 2011-2022.

[15] On these bases, furyl derivative $\mathbf{3 b f}$ and $\beta$-adduct $\mathbf{3 b j}$ feature a 4 'S stereocenter instead of $4 ' R$, due to CIP priority rules.

[16] For a recent review on the stereoselective synthesis of quaternary proline analogues, see: M. I. Calaza, C. Cativiela, Eur. J. Org. Chem. 2008, 3427-3448.

[17] Interestingly, this tetracyclic derivative proved to be quite stable at r.t., and every effort to promote a rearomatization of the indole ring under acidic or basic conditions failed.

[18] a) T. Okino, Y. Hoashi, T. Furukawa, X. Xu, Y. Takemoto, J. Am. Chem. Soc. 2005, 127, 119-125; b) A. Hamza, G. Schubert, T. Soós, I. Pápai, J. Am. Chem. Soc. 2006, 128, 13151-13160.

[19] The peculiar role exerted by the catalyst in controlling the $s$-trans conformation of the dienolate in the transition state was also confirmed by several control experiments, in which $\mathrm{Et}_{3} \mathrm{~N}$-promoted VMcR between $(E)$ - and $(Z)-\mathbf{1 b}$ and $\mathbf{2} \mathbf{b}$, without the assistance of the dual cinchona-thiourea catalyst, afforded the corresponding adduct with an inverted $E$ selectivity (See Table S1 in the Supporting Information).

[20] The calculations were performed at the M06-2X/def2TZVPP-IEFPCM(toluene)//M06-2X/6-31G(d) level of theory, using Gaussian 09 (see Supporting Information): a) J.-L. Zhu, Y. Zhang, C. Liu, A.-M. Zheng, W. Wang, 
J. Org. Chem. 2012, 77, 9813-9825; b) M. N. Grayson, K. N. Houk, J. Am. Chem. Soc. 2016, 138, 9041-9044.

[21] The conformational preferences of the thiourea catalyst II by rotation about its $\mathrm{C} 8-\mathrm{C} 9$ and $\mathrm{C} 9-\mathrm{C} 4$ ' single bonds were also studied. It was found that open conformers (C8-C9 bond rotamers) were strongly favoured with respect to the closed ones, in accordance to what recently reported. See: A. Sengupta, R. B. Sunoj, J. Org. Chem. 2012, 77, 10525-10536. Moreover, antiopen conformer and syn-open conformers (C9-C4' bond rotamers) were similar in energy, but the anti-open arrangement causes less steric hindrance in the region where the reactions are supposed to occur, so only the anti-open conformer of the catalyst was considered for further calculations. See also Ref. 20b

[22] In addition to the reported computational analysis, the $Z$-geometry of the exocyclic double bond within 1a' resulted in analogy with a $N$-Boc dienolsilane congener (Z)-20 (not shown) obtained as a single isomer from isopropyl ester $(E)-\mathbf{1 h}$ and whose configuration was certified by 2D-NOESY NMR analyses. See the Supporting Information for details. 


\section{FULL PAPER}

(E)-3-(Alkoxycarbonyl-2-Alkyliden)-2-

Oxindoles: Multidentate Pronucleophiles for the Organocatalytic, Vinylogous Michael Addition to Nitroolefins

Adv. Synth. Catal. Year, Volume, Page - Page

Claudio Curti,* Lucia Battistini, Andrea Sartori, Gloria Rassu, Giorgio Pelosi, Marco Lombardo, Franca Zanardi
- captodative in situ-generated dienolate $\circ$ additional handle $\left(\mathrm{CO}_{2} \mathrm{R}^{3}\right)$ for geometry control - highly functionalized chiral targets

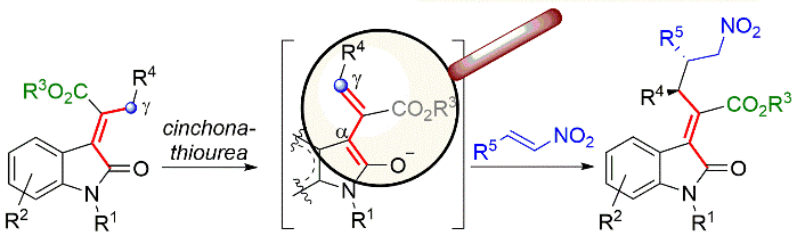

